\title{
18
}

\section{USING TASK-BASED LANGUAGE TEACHING IN THE SECOND LANGUAGE CLASSROOM}

\section{Developing global communication competencies}

\section{Chris Sheppard}

\section{Summary}

English as a foreign language needs to be taught so that it is useful in practice. However, currently, in the Japanese education system the approach is often to teach only the logical grammatical structure of English. Even though the Japanese Ministry of Education recognizes that English needs to be taught as a practical skill, beyond requiring that teachers improve their students' second language proficiency, it offers very little guidance on what should be done in the classroom. In this chapter, task-based language teaching (TBLT) is introduced as a method which can be used to develop English as a second language skills beyond grammatical knowledge. Three studies, which demonstrate how language learning tasks can be used to develop three dimensions of language skill (accuracy, complexity, and fluency), are offered as evidential support that this approach is effective.

\section{Introduction}

Arguably, the focus of education needs to change to skills required for the 21st century. One of the most important of these skills is the ability to communicate effectively in relevant communities (Ananiadou \& Claro, 2009). Traditionally, these communities have been local, and individual's native languages were sufficient. However, increasingly, individuals have become members of global communities, which require the use of a second language - very often English (Phillipson, 2008). Japan is no exception. Today, Japanese individuals often find themselves in situations where English is the common language of the communities they participate in. 
In recognition of these changes, recent reforms in Japan have attempted to refocus English education. College graduates are now expected to be able to use English to participate in the global economy (MEXT, 2003), and there has been some limited success in developing the English skills of native Japanese. For example, Super English High Schools where the classes are conducted in English, have furthered the communicative abilities of their students. Unfortunately, these successes have largely not extended to the general Japanese population (Nishino \& Watanabe, 2008).

There are numerous reasons for such limited success, but two stand out. The first is that there are dual purposes for English education in Japan, and the second is the government's resourcing of English teaching. Although the government has attempted to refocus on teaching English as a communicative skill through various initiatives, it is often still taught as an academic skill directed towards entrance examinations (Butler \& Iino, 2005). These examinations are often perceived to be designed to test English grammatical understanding and comprehension of complicated reading texts which are understood through grammar-translation. (However, Seki et al., 2011, rebuts this perception.)

Entrance examinations have a washback effect on the Japanese education system. In spite of being required to focus on the development of English as a communication skill, teachers at secondary level must also focus on students' examination preparation (Allen, 2016). The more schools move away from "teaching to" entrance exams and attempt to develop communication skills, the more students participate in what has been called "shadow education," or the after-school juku, which, in 1997, 75\% of public junior high school students attended (Højlund Roesgaard, 2006). Many of these juku teach solely towards entrance examinations. One key purpose for learning English, then, is to acquire discrete grammatical knowledge and grammar-translation skills, while the second communication purpose gets less attention.

The second reason for limited success is lack of government resourcing. In its 2003 document, the Ministry of Education, Sport, Science, Culture and Technology (MEXT) focused on the development of teachers by requiring improvements in their English proficiency, not by training them how to develop their students' communication skills. MEXT stated that "almost all English teachers will acquire high English skills" (2004, p. 4) and set a goal of 550 points in the Test of English as a Foreign Language (TOEFL, https:// www.ets.org/toefl) for new teachers. This approach to English education is also apparent in their action plans, which aim to "increase the use of Assistant Language Teachers" (unqualified native or near-native English speakers) and to use "local personnel who are proficient in English" (in Butler \& Iino, 2005, p. 34).

This ignores the professional component of English education, and it makes the common assumption of nonexperts in Japan: to be a good language teacher only subject proficiency is necessary. However, appropriate tools and professional development could transition teaching content from the academic knowledge 
required by the entrance examinations to tasks which develop second language communication skills.

This chapter introduces task-based language teaching (TBLT), which aims to develop second language as a communication skill. Its purpose is to provide a framework which can be applied by teachers at any curriculum level to their language classrooms. First, theoretical support for the skill-based learning, on which TBLT is based, is presented. This is followed by an introduction to TBLT. The final section gives evidence for the utility of this approach. Although this chapter frames the use of TBLT in Japanese English language education, it is effective in any educational context which aims to teach language for communication.

\section{Learning language as a skill}

For adult learners, the skill-based learning of a second language requires the development of implicit knowledge (Ellis, 2004). Similar to Anderson's (2015) procedural knowledge in his Adaptive Control of Thought-Rational (ACT-R) model, it is an unconscious knowledge of both the linguistic structure of a language and also the ability to use this information to communicate. Using Ellis' (2017) example, a native-English-speaking 3-year-old is able to apply the rules of the language, effortlessly and unconsciously, while speaking, but she will be unable to verbally explain them because she has an implicit knowledge of the language, not an explicit one.

Implicit knowledge is represented in the brain by connectionist networks (Roberts, 1998), reflecting the neurobiological reality of the neurons linked by a network of synaptic connections. Interestingly, Rumelhart and McClelland (1986) researched the utility of connectionism as a metaphor for language knowledge in the 1980s and demonstrated that a Parallel Distributed Processing network was able to "learn" and "represent" the regular and irregular past tense of English verbs from the input alone.

It may be useful, at this point, to contrast implicit knowledge with explicit knowledge (known as declarative knowledge in Andersen's ACT-R model). Explicit knowledge is the knowledge of how to do something (Ellis, 2004). In language learning, it might be the knowledge of a grammatical rule. One characteristic of explicit knowledge is that it is accessible consciously and can be verbalized. An outcome of adult language education in many countries is explicit knowledge, which is useful but insufficient for actual communication.

DeKeyser (2007), drawing on Anderson (2015), explains that one way to develop second language production skills is through repetitive practice in three stages: cognitive, associative, and automatic (which Anderson calls autonomous). The first cognitive stage of skill learning starts under conscious control, usually by the application of explicitly known grammatical rules and vocabulary. This conscious process creates an implicit exemplar of the rule (i.e., a single application of the rule in context). Once several such exemplars are created, the 
learning moves to the next step. This conscious process is taxing on our cognitive resources and requires time.

The second, associative stage of learning involves the partial activation of the exemplars. The context of the communication activates associations related to one or more of the exemplars and, hence, they are recalled. However, as the connections are weak, exemplars may be slow to activate, or fail altogether. In this case, the conscious process takes over and creates a new exemplar. When a previous exemplar is partially activated, the new exemplar is then associated with it. Thus, the associative stage is a process of creating linked contextualized exemplars. Another form of associative learning occurs when there is partial or full activation of the exemplar which is consciously manipulated to better match the communicative purpose of the production. This process also creates a new exemplar, which is likewise connected to the original (see Logan, 1988). These exemplars make up procedural knowledge.

In the last, automatization stage, the context will activate the interconnected network of exemplars and autonomously produce a new exemplar which matches the communicative context. The more exemplars produced, the greater the levels of activation and the faster the production becomes. This further develops the procedural knowledge network.

For successful language learning, the teacher needs to create an environment which will guide students through this process from explicit to implicit knowledge. According to DeKeyser (2007), three conditions need to be fulfilled for this. The first is that the learning should be fully contextualized through meaningful communication. The process of learning is the creation of new exemplars connected to an existing knowledge network. Without this connection, while new exemplars may be created, it will be more difficult to access them.

The second condition for effective skill learning is repetition. Second language acquisition follows "the same power function learning curve as the acquisition of other cognitive skills" (DeKeyser, 1997, 2007), and so to attain automaticity the learner needs contextualized repetition. In his experiment, DeKeyser found that learning morpho-syntactic rules in context could be modeled by this power law. (The power law describes the relationship between practice and learning, often measured by reaction time. The first few repetitions result in great gains in performance, and thereafter each repetition results in a diminishing return in improvement.) This was also true for reaction times and for accuracy rates in receptive and productive tasks. A considerable amount of repetition was required to achieve automaticity on a picture selection comprehension task. It took a total of 15 hour-long sessions over a period of 8 weeks.

The third condition for skill-based learning is to have sufficient processing capacity available for the learning to occur. The conscious components of language skill learning take place in working memory (Baddeley, 2003), a cognitive system with a limited capacity that is responsible for temporarily holding information available for processing (Miyake \& Shah, 1999). Activated knowledge from our long-term memory is linked to auditory and visual sensory inputs in 
working memory (Baddeley, 2015). Limited capacity in working memory means that activated memories decay quickly and the executive systems lose access to them. Likewise, the auditory and visuo-spatial loops which hold perceptual auditory and visual information respectively are also limited, as is our ability to attend to activated information.

Second language learning taxes a student's available processing capacities. If the processing requirements exceed the resources available, learners will prioritize the meaning over the form of the language (VanPatten, 1990). This is counterproductive if the primary aim of a learning event is to encode a new exemplar of the form of the language.

\section{Description of the method}

\section{Teaching language as a skill: Task-based language learning}

Second language education requires a systematic method which will enable the teacher to ensure that the three necessary conditions - contextualization, repetition, and sufficient capacity - are met to enable learners to develop their second language for communicative purposes. This section describes task-based language teaching (TBLT). It defines language learning tasks and describes how they can be organized into a pedagogic syllabus.

\section{What is a task?}

Though there are many different definitions of a language learning task (Ellis, 2003) the following definition from Van den Branden (2006, p. 4) is useful. He suggests "a task is an activity in which a person engages in order to attain an objective, and which necessitates the use of language." For example, imagine being in a store and unable to find an item. Finding that item is the objective. One choice is to use language and ask the shop attendant for help. The attendant's response will likely be an explanation of where the item is. The successful outcome to this task would be locating the item after following the instructions the attendant provided. So, a language learning task is one used with the goal of developing language skills in the process of achieving an objective.

Many classroom learning activities lack such a purpose. Their objectives include learning by using the language in some noncommunicative way. Examples are completing textbook exercises which require learners to change a verb from the present tense into the past tense, or translating a sentence from Japanese to English, or mimicking sentences spoken by the teacher. In each of these cases, the learning goal is to accurately use the language and the successful outcome of the language learning exercise is assessed by how accurate the use of the target language is.

What sets a language learning task apart from other learning activities, is that it has a dual purpose. The first purpose is achieving the communicative outcome. 
In the example above, this was finding the item in the shop. The second is the language learning goal of the task. This can be as general as developing a learner's holistic language proficiency, or as specific as learning to apply the past-tense to verbs. In the shopping task above, the language learning goals could be achieving skill in making requests for information, or in understanding directions, depending on how the teacher designed the task.

The easiest way to determine if the learning activity is a task or an exercise is to question whether the learning goal and the outcome of the activity are the same. If the outcome and the goal of the activity are the same, then it is a language learning exercise. For example, if the goal is to produce the past-tense, and the outcome of the activity is to have changed the verbs in a sentence from the present tense to the past tense, then the goal and the outcome are the same. On the other hand, if the outcome and goal are different, then it is a language learning task. For example, if the outcome of a learning activity was to have used language to successfully locate a product in a shop but the language learning goal was to accurately comprehend instructions, then the goal and the outcome are different.

Another characteristic of tasks is their authenticity. Authenticity is the degree to which a classroom task is reflective of a real-world task (Gilmore, 2007). For example, if the learner is required to phone and order a pizza, then a successful task outcome would be to have a pizza delivered to the classroom. A less authentic task has no such real-world correspondence. An example might be a picture story task, where one student describes a series of pictures, while the other student listens and puts the same jumbled pictures into time order. Most people are unlikely to find a real-world application for this kind of task.

Some TBLT practitioners suggest that all tasks ought to be authentic to best foster language development (Long, 1985). However, complete authenticity in the classroom is difficult. In Japan, where English is a foreign language, for example, there is little opportunity to create truly authentic tasks - the restaurant staff will answer the phone in Japanese. Ellis (2003) suggests that for tasks to be of pedagogic value, they need only be authentic in their ability to foster authentic communication between the task participants. In other words, if the task elicits language which is able to create contextualized exemplars, then it is sufficient for the purposes of language learning. Students who are role playing restaurant staff can respond to other students who in turn are role-playing customers.

\section{What does the use of tasks achieve?}

One of the criticisms aimed at TBLT is that while doing language tasks, learners are able to use any language and strategic resource they have to achieve the set outcome (Ellis, 2003). Sato (2010), for example, found that the university participants in his task-based study did not use the target structure, in his case, the present perfect, at all. This suggests that teachers will find it difficult to use tasks to focus on one grammatical feature at a time, as is currently common. 
Skehan (1998) believed that, in addition to designing tasks which elicit the communicative use of grammatical features, teachers should aim to develop complexity, accuracy, or fluency. Also due to the learners' limited processing capacity, a task should focus on improving only one of these dimensions at a time. Housen, Kuiken, and Vedder (2012) demonstrated that these three dimensions of language can be independently taught. Basing tasks on each of these dimensions in turn is also a practical way to organize language learning and language curricula.

Accuracy focuses on the correct use of the language. Accuracy-focused tasks are aimed at building a repertoire of linguistically correct exemplars which can be drawn on later.

Complexity can be lexical or grammatical. Lexical complexity pertains to the production of language with a greater variety of vocabulary items. Grammatical complexity refers to the level of sophistication of expressions of language "rules" and structure. Consider, for example, the number of clauses in a sentence. More clauses make it longer and grammatically more complex. Tasks developing complexity direct the learner's attention to expressing more involved content and ideas during their performance. The intention is that by doing so the learner will be able to build on and expand their existing linguistic knowledge in new contexts, often by using the grammatical structures learned explicitly. This process can be linked to the associative stage of skill learning.

Fluency indicates the speed at which someone can process language. Tasks which focus on fluency require learners to process content and use familiar language as quickly as possible without losing much accuracy. The goal of fluency development is to activate previously acquired knowledge, and thus strengthen and increase the connections in the brain, as occurs in the automatizing stage of skill learning.

\section{Using tasks in the classroom}

When tasks are used in the classroom, the learner's attention should be oriented to aspects of language use which will meet the required outcomes and language goals most effectively, either through the design of the task itself, or through the design of the individual lessons.

\section{Task design features}

Ellis' (2003) general task framework describes several ways to design tasks. The features of task design that he differentiates are: the input, the conditions, the cognitive processes, and the outcomes. The input includes how information is provided to the learners; pictorially, orally, or in written form, for example. The task conditions will describe how the information will need to be shared between the students in order to achieve the outcome. Do the students have different information, or the same information? Does all the information come 
from one student, or is the information shared? The cognitive processes refer to the function of the communication: an exchange of information, opinion, or an explanation. Finally, in what form will the outcome be expressed: pictorially, orally, or written? (See Skehan, 2018, for a more recent classification).

\section{Task procedures}

In addition to identifying the task type, teachers can direct learner attention through the design of the lesson, beginning with the pre-task phase, during the task phase, and in the post-task phase (Ellis, 2003). The pre-task phase prepares the learners. It will usually include an explanation of the communicative purpose and the criteria for successful completion. It may include, for example, providing a model exemplifying the required performance. It could also be an explicit reminder to the learners of a grammatical form which would assist them in the completion of the task. During the task itself, the teacher controls such things as materials and resources available, who gets what information, the time available, and the number of participants. In the post-task session, for example, the teacher could provide successful examples of the same task the learners had just completed for comparison, and give feedback to the students on their performance. Alternatively, the teacher could ask the students to evaluate their own performance based on the outcomes and learning goals of the tasks.

\section{The task-based curriculum}

Tasks can be central to a curriculum, as in task-based language teaching, or peripheral elements such as in task supported language teaching (Ellis, 2018). In order to use tasks successfully in either approach, they need to be selected and ordered effectively (Nation \& Macalister, 2010).

Students' needs should be paramount and task selection should depend on how and why students will use the target language in the future. As explained previously, one need for many Japanese students is to pass the university entrance examination. Other Japanese students, for example graduate engineering students, have more specific needs, like being required to present their research at international conferences and write papers for conference proceedings in English. Only relevant tasks leading to proficiency in these areas should be selected for them.

Learners may have a need to use English to present research, but such authentic tasks are very complex and successful outcomes are unlikely. A task-based curriculum will therefore need to gradually build up skills starting from students' current levels and ending at a point where they can perform the target tasks. This is done by gradually increasing task complexity (Robinson, 2001). (Task complexity is a characteristic of the task and is different to the complexity described above which is a feature of the language used while performing a task). Cognitive complexity results from the degree to which the structure of 
a task demands resources in order to successfully achieve the outcome. To illustrate, a task with more components is more complex; i.e., a picture story with ten frames is more complex than a picture story with five frames. In summary, designing tasks to gradually increase fluency, accuracy, and complexity is key to a TBLT curriculum.

The argument here is that the task is an effective unit of design in a classroom focused on developing language as a communicative skill. It provides a framework to contextualize communication and enables learners to make the necessary exemplars and connections to develop increasingly complex language skills. In other words, a task-based curriculum provides teachers with a way to organize the development of a learner's language from their current level to their target levels.

\section{Evidence for effectiveness}

This section introduces evidence from three studies conducted by the author that suggests tasks, alone and as part of a curriculum, are effective in improving the accuracy, complexity, and fluency of second language learners. The first study examines how feedback during task performance can improve accuracy. The second study describes how gradually increasing task complexity develops the linguistic complexity of written output. The third study examines the limits of task repetition as a means of developing fluency.

\section{Developing accuracy}

TBLT provides teachers with mechanisms to focus on the forms of language and the accuracy of its production. Feedback may be one such mechanism. Although often eschewed in communicative language teaching as being ineffective and even detrimental to the learning process (Krashen, 1985), a more recent meta-analysis of research examining the efficacy of feedback has shown it to have a positive effect on learning (Li, 2010). Sheppard $(2006,2016)$ demonstrated that feedback, in the form of recasts, was an effective way to improve the accuracy of learner output.

As mentioned, a problem with task-based language production is that learners can use any resources they have available to attain the outcome of the task, making it difficult to predetermine a focus on any grammatical feature. In addition, there is a lower likelihood that learners will notice and respond to any feedback. VanPatten (1990) also pointed out that learners will focus on meaning first, and then only if any processing resources remain, the form of the language.

Swain's (1995) output hypotheses, however, provides for a mechanism in language production through which learners shift from a focus on meaning to form, which she called "noticing the gap." According to Levelt's (1989) Speech Production Model, this is the point during production where the learner notices that they are unable to formulate a conceptualized message. Sheppard $(2006,2016)$ 
attempted to determine if noticing the gap would lead learners to be oriented to feedback which was aimed at filling this gap and result in increased accuracy in production in subsequent task performance.

To investigate this, 40 Japanese university students were recruited and placed into either a control group or a repair group. Both groups repeated a ten-frame picture story task three times (time 1, time 2, and time 3) and then a new task of the same type (time 4). Upon completion of the first task (time 1), the repair group underwent a stimulated recall procedure where the participants watched a video of their own performance and responded to questions about "what they were thinking" any time the video showed pauses, repetitions, or reformulations during their oral task output. Whenever the participants indicated that they had "noticed a gap," a recast, or a phrase to fill the gap, was provided. The control group, on the other hand, participated in a general conversation about content unrelated to the task for an equivalent amount of time.

The results for the accuracy of production, as measured by the percentage of error-free clauses, are shown in Figure 18.1. The performance accuracy of the repair group increased significantly at time 2 when compared to that of the control group, and the accuracy of the performance on a new task stayed significantly higher at time 4 .

These results show that feedback aimed at filling noticed gaps assists learners to produce more accurate language. The change is probably due to a combination of incorporating language contained in the feedback, thus creating new exemplars, and to more attention being focused on accurate performance, reformulating existing exemplars. This study demonstrates that tasks can be designed to increase accuracy.

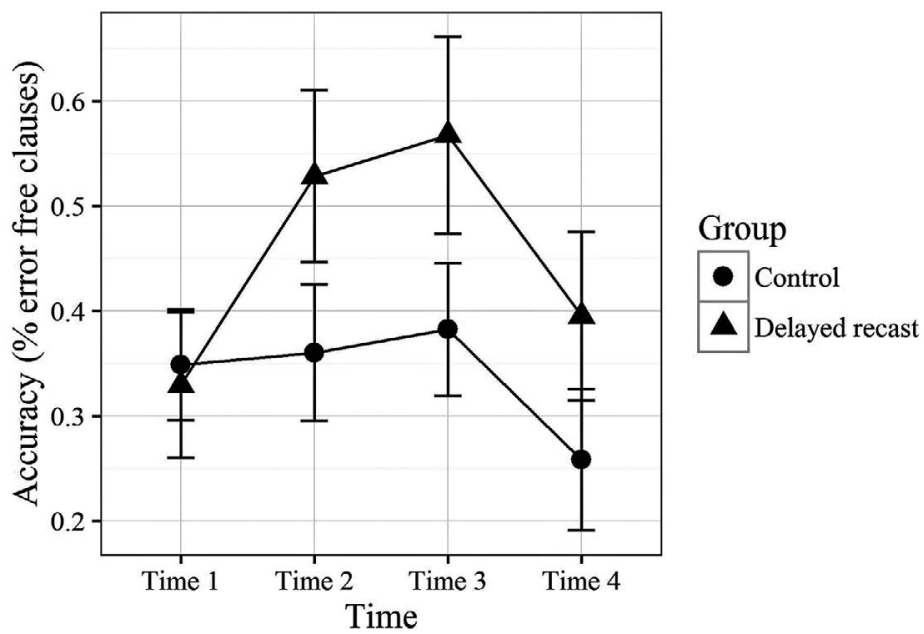

FIGURE 18.1 Oral task production accuracy by group of three task repetitions (time 1, time 2, and time 3 ) and a new task of the same type (time 4). 


\section{Developing complexity}

As described above, tasks can be ordered based on complexity. The next study described set out to demonstrate that increasing task complexity over 3 years results in performance improvements (Sheppard \& Ellis-Tanaka, 2011). The study was conducted within a large-scale English for Specific Purposes (ESP) program in the science and engineering faculty of a Japanese university. This program aimed to develop the communication skills the learners would need to participate in the international community as researchers in the fields of science, technology, engineering, and mathematics (STEM). One goal of the program was to develop the ability to report research findings in written form in conference proceedings. The curriculum was built around repeating tasks, which gradually increased in complexity.

The first rotation was completed in the first year during two courses called Academic Lecture Comprehension 1 and 2 (ALC 1 and ALC 2). Learners completed a series of note-taking tasks requiring a one-way information transfer from the teacher to the students. The information was presented in lecture form, and the tasks were varied by increasing the complexity of the information structures. Each task represented the structure of the various sections of a research paper. For example, the course began with process-structured lectures, and finished with a research presentation using an Introduction-Method-Results-and-Discussion structure (see Sheppard, 2019).

The second rotation of the cycle was executed in the first semester of the second year in Concept Building and Discussion 1 (CBD 1). The information structures were the same; however, this time the tasks were two-way, the information was shared between students. Again, the task complexity was gradually increased by varying the information structures. An example of a task used here is "listen and draw," where information was provided orally to complete a graph or a table (see Anthony, Rose, \& Sheppard, 2010).

The third rotation increased the complexity in two ways in Concept Building and Discussion 2 (CBD 2). The first required individual students to generate the content of the task, through completing the individual steps of a research project. The task content was also linked so that subsequent task content was dependent on the outcomes of the previous tasks. The task order followed the steps of an empirically based research project: introduction, method, results, and then discussion. An example is an opinion-gap task, where the students discussed their opinions of the answer to a shared research question using their data as supporting evidence. The desired outcome was to reach an agreement between the participants (see Rose \& Anthony, 2010).

Finally, Technical Writing 1 (TW 1) followed a project-based approach, rather than a task-based approach. The students were required to complete a research project following the same steps as in the third repetition. However, this time, the content needed to be related to their field of study, thus increasing the complexity. 
The program was evaluated in terms of the development of grammatical complexity in writing over a 3 -year period. Samples of paragraph summaries from the first part of the first rotation, and multiple-paragraph summaries from the second part were analyzed. The second rotation samples came from written summaries of oral tasks. The written samples from the third rotation were four-page IMRAD research reports. Similarly, the written samples from the final rotation were the final reports which simulated conference proceedings papers. The target sample, for comparison purposes, was taken randomly from chemistry and engineering IEEE conference proceedings published in 2010. Nine samples were taken from each level.

Complexity was measured in three ways: the average length of the sentences in words, verbs per sentence, and words per clause. The data was taken from intact classes taught by the researcher over several years. However, as the design was not longitudinal, each data set represented a completely different group of students.

The results are displayed in Figure 18.2, Figure 18.3, and Figure 18.4. The sentence length (Figure 18.2) and the clauses per sentence (Figure 18.3) demonstrate a development towards the target. However, the average number of words per clause (Figure 18.4) does not show improvement.

It is also clear that the proficiency of the class could have affected these results. The class representing the second part of the first rotation (ALC 2) averaged TOEIC-IP scores of more than 750 points, much higher than other classes' scores. This higher student proficiency may account for the higher complexity of written production apparent in the results for ALC 2.

Overall, the results show that using task complexity to order tasks in a taskbased curriculum does appear to improve the written complexity of Japanese

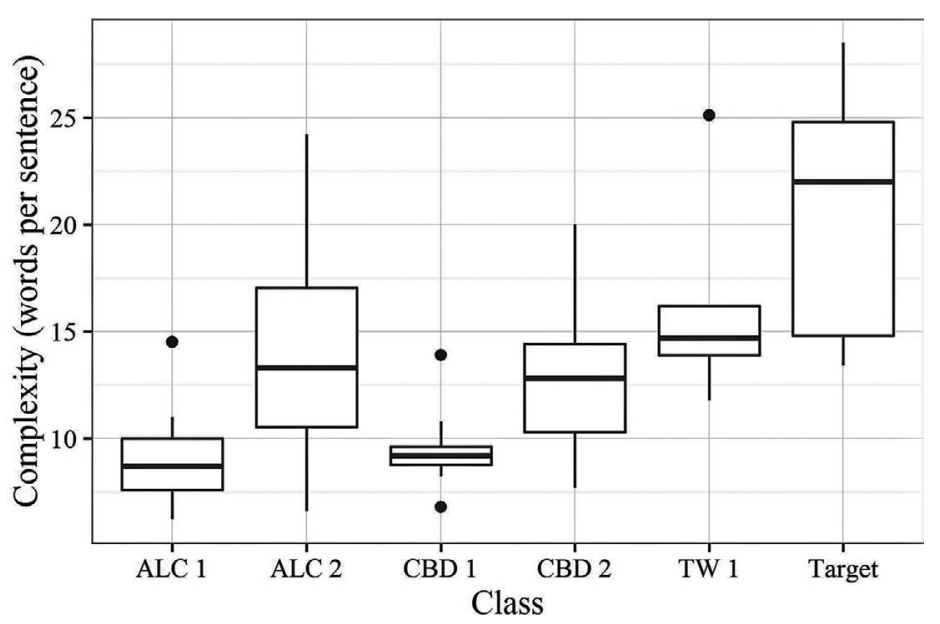

FIGURE 18.2 The complexity (words per sentence) of written production by class. 


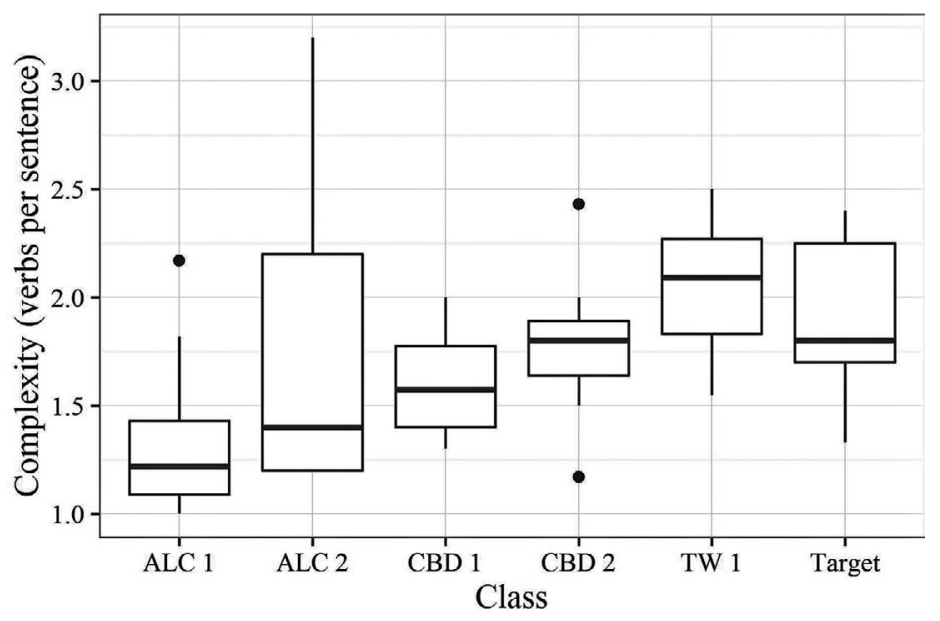

FIGURE 18.3 The complexity (verbs per sentence) of written production by class.

STEM students' writing, with the number of clauses per sentence even reaching the target standard. However, this improvement does not extend to all dimensions of complexity (i.e., not in the average words per clause). The reason for the improvement is most likely from a combination of task-demands, which required more complexity in the written expression to achieve the expected task outcome, and proficiency improvements gained through participating in a task-based curriculum. It should be reiterated here that as each of the class groups were very different and that because the tasks themselves were very different, the improvement in the complexity of writing was also affected by other factors.

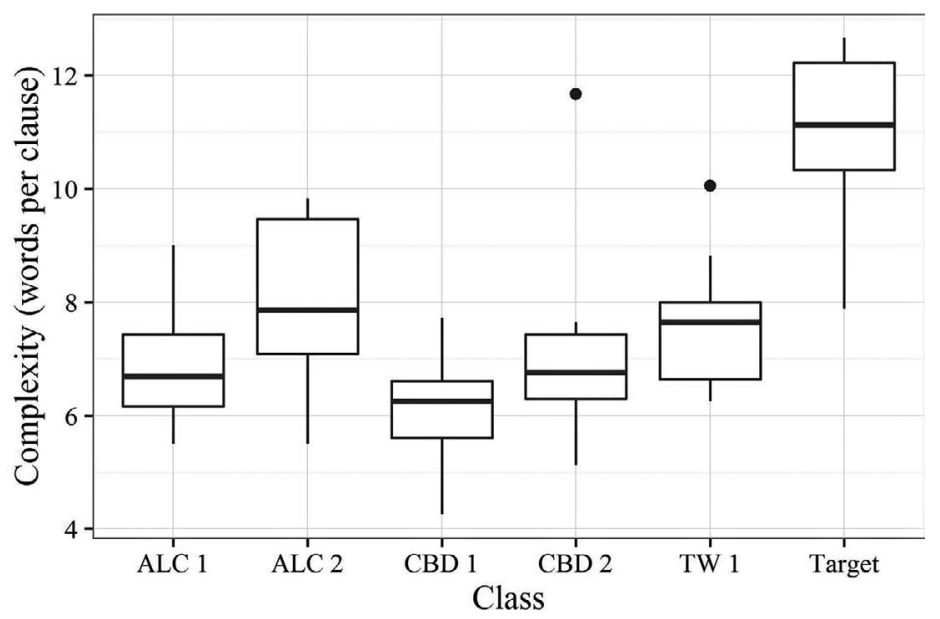

FIGURE 18.4 The complexity (words per clause) of written production by class. 


\section{Developing fluency}

The final study described here, reported in Sheppard and Ellis (2018), demonstrates that task-repetition is effective for developing oral fluency on performance of the same task but does not extend to performance on the same task-type. Meaningful repetition is central to the development of autonomous skills (Anderson, 2015), that is, the ability to use a second language fluently (DeKeyser, 1997). Thus, repeating the same task many times would likely have an effect of improving spoken fluency (Bygate, 2001).

The study reported here looked at the spoken performance of participants in two groups who completed a picture story task. (The data came from the same data set, but from different groups as in the accuracy study reported in the previous section.) The first group just repeated the task, whereas the second group completed the same stimulated recall procedure as described previously, but there was no further intervention. Fluency was measured in terms of the pruned words per minute, where reformulations and repetitions, including fillers were deleted before calculating the speech rate. The first ten-frame picture story was repeated three times. Time 1 and time 2 took place within 30 minutes of each other, while time 3 was two weeks later. The fourth repetition (time 4) was of the same task-type (a ten-frame picture story), but with new content.

The results are shown in Figure 18.5. The fluency of production increased for both groups in time 2. Although this improvement was marginal for the task-repetition group, it was much greater for the stimulated recall group. The improvement was maintained for the two groups two weeks later, but the speech rate of the stimulated recall group dropped back to that of the task-repetition group in the new task.

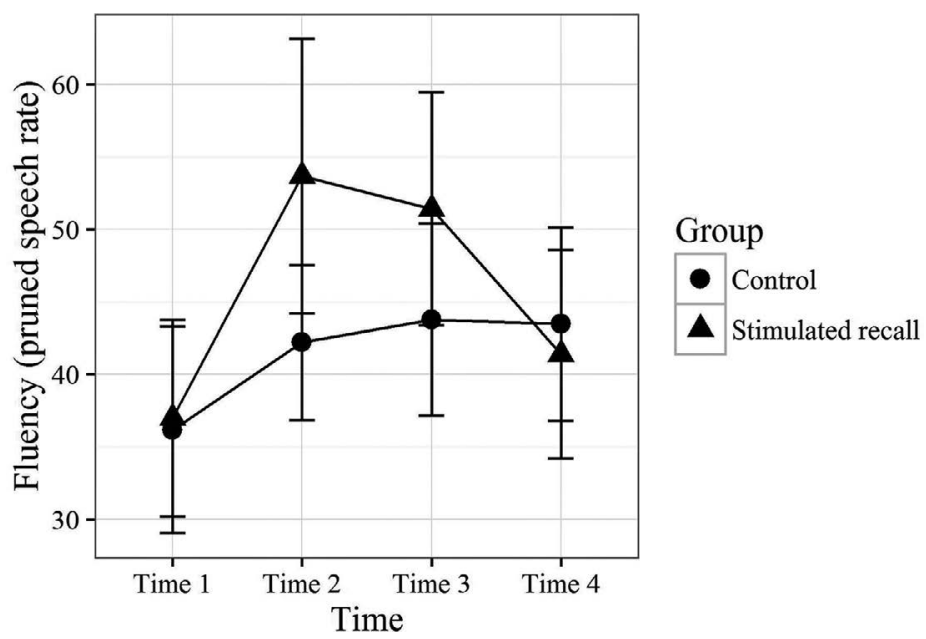

FIGURE 18.5 The oral fluency by group of three task repetitions (time 1, time 2, and time 3) and a new task of the same type (time 4). 
Overall, the results show that while task-repetition is marginally beneficial initially, this improvement is not backed up by further task repetitions. There are two possible reasons for this which will impact on how task-repetition can be used to improve spoken fluency in the classroom. The first is that 2 weeks between tasks is likely too long to foster fluency development. This is because the memory activations gained through the first repetitions are lost, so the exemplar network is not developed. The second is that the amount of repetition is likely to be insufficient. According to the DeKeyser (1997) study reported previously, 15 hour-long sessions over 8 weeks were necessary for improvement. The study here only had three repetitions separated by 2 weeks. Ahmadian (2011) demonstrated improvements in fluency from mass task-repetition (11 times) transferred to a new task. Further evidence for a possible effect of increasing the number of repetitions comes from the superior improvement of the stimulated recall group. It is likely that the stimulated recall procedure acted as further repetition. The opportunity to view their video and consider their performance further maintained the mental activations, resulting in improved fluency. Thus, in order to further improve fluency, larger amounts of meaningful repetition, with smaller intervals between repetitions may be necessary.

\section{Conclusion}

Second language teachers, including those in Japan, need the tools required to teach language for practical communication. One such tool is TBLT. Tasks in TBLT require the learner to focus on the form and the meaning of the language simultaneously during communicative task performance. They have been shown to develop the accuracy, complexity, and fluency of language which make up the individual components of the knowledge and skills required to communicate in a second language.

The TBLT teacher is able to manipulate tasks in several ways to teach communicative skills. Tasks can be designed differently depending on, for example, the distribution of information, the outcome required, and the conditions under which the tasks are completed to help learners focus on both the form and the meaning of the language simultaneously. For example, the complexity study described in this chapter demonstrated that tasks which require the one-way passage of information are likely to elicit less complex language than a two-way task.

The task procedures can also be manipulated. Teachers can design pre-task, during-task, and post-task interventions to assist the learners to focus on the required performance. Task repetition is one procedure that has been shown to have the potential for developing fluency. The accuracy study demonstrated that the provision of feedback to learners when they were aware of a gap helped improve the accuracy of their performance.

Teachers also control the ordering of tasks in a TBLT curriculum. Taskcomplexity can be used both to classify tasks and order them in a curriculum. 
The complexity study showed that by increasing the complexity of the tasks over a 3-year period, STEM students were able to develop more sophisticated written production, finally achieving target proficiency in one of the measures. While TBLT is not suitable for all situations and all contexts, this chapter has introduced how TBLT can successfully be used to develop the communicative language skills of students.

\section{References}

Ahmadian, M. J. (2011). The effect of 'massed' task repetitions on complexity, accuracy and fluency: Does it transfer to a new task? The Language Learning Journal, 39(3), 269-280.

Allen, D. (2016). Japanese cram schools and entrance exam washback. The Asian Journal of Applied Linguistics, 3(1), 54-67.

Ananiadou, K., \& Claro, M. (2009). 21st Century Skills and Competences for New Millennium Learners in OECD countries. OECD education working papers, No. 41. Paris, France: OECD.

Anderson, J. R. (2015). Cognitive psychology and its implications (8th ed.). New York: Macmillan.

Anthony, L., Rose, R., \& Sheppard, C. (2010). Concept building and discussion: Foundations (2nd ed.). Tokyo, Japan: DTP.

Baddeley, A. (2003). Working memory and language: An overview. Journal of Communication Disorders, 36(3), 189-203.

Baddeley, A. D. (2015). Working memory in second language learning. In Z. Wen, M. B. Mota, \& A. McNeill (Eds.), Working memory in second language acquisition and processing (pp. 17-28). Bristol, UK: Multilingual Matters.

Butler,Y. G., \& Iino, M. (2005). Current Japanese reforms in English language education:The 2003 “action plan". Language Policy, 4, 25-45.

Bygate, M. (2001). Effects of task repetition on the structure and control of oral language. In M. Bygate, P. Skehan, \& M. Swain (Eds.), Researching pedagogic tasks (pp. 33-58). Essex, UK: Routledge.

DeKeyser, R. (1997). Beyond explicit rule learning: Automatizing second language morphosyntax. Studies in Second Language Acquisition, 19(2), 195-221.

DeKeyser, R. (2007). Skill acquisition theory. In B.VanPatten \& J.Williams (Eds.), Theories in second language acquisition: An introduction (pp. 97-114). Mahwah, NJ: Routledge.

Ellis, N. C. (2017). Implicit and explicit knowledge about language. In J. Cenoz \& D. Gorter (Eds.), Language awareness and multilingualism. Encyclopedia of language and education (pp.113-124). Boston, MA: Springer.

Ellis, R. (2003). Task based language learning and teaching. Oxford, UK: Oxford University Press.

Ellis, R. (2004).The definition and measurement of L2 explicit knowledge. Language Learning, $54,227-275$.

Ellis, R. (2018). Reflections on task-based language teaching. Bristol, UK: Multilingual Matters.

Gilmore, A. (2007). Authentic materials and authenticity in foreign language learning. Language Teaching, 40(2), 97-118.

Højlund Roesgaard, M. (2006). Japanese Education and the Cram School Business: Functions, Challenges and Perspectives of the Juku. Copenhagen, Denmark: NIAS Press.

Housen, A., Kuiken, F., \& Vedder, I. (Eds.). (2012). Dimensions of L2 performance and proficiency: Complexity, accuracy and fluency in SLA. Amsterdam, The Netherlands: John Benjamins.

Krashen, S. D. (1985). The input hypothesis: Issues and implications. London, UK: Longman. 
Levelt, W. (1989). Speaking: From intention to articulation. Cambridge, MA: MIT Press.

Li, S. (2010). The effectiveness of corrective feedback in SLA: A meta-analysis. Language Learning, 60(2), 309-365.

Logan, G. D. (1988). Toward an instance theory of automatization. Psychological Review, 95(4), 492-527.

Long, M. H. (1985). A role for instruction in second language acquisition: Task based language teaching. In K. Hyltenstam \& M. Pienemann (Eds.), Modelling and assessing second language acquisition (pp. 77-99). Clevedon, UK: Multilingual Matters.

MEXT. (2003). Eigo ga tsukaeru nihonjin no ikusei no tameno koudoukeikaku [An action plan to cultivate Japanese with English abilities]. Retrieved from www.mext.go.jp/b_menu/ shingi/chukyo/chukyo4/007/gijiroku/03032401/009.pdf

Miyake,A., \& Shah, P. (Eds.). (1999). Models of working memory: Mechanisms of active maintenance and executive control. Cambridge, UK: Cambridge University Press.

Nation, I. S. P., \& Macalister, J. (2010). Language curriculum design. New York: Routledge.

Nishino, T., \& Watanabe, M. (2008). Communication-oriented policies versus classroom realities in Japan. TESOL Quarterly, 42(1), 133-138.

Phillipson, R. (2008). The linguistic imperialism of neoliberal empire. Critical Inquiry in Language Studies, 5, 1-43.

Roberts P. (1998). Implicit knowledge and connectionism: What is the connection? In K. Kirsner, C. Speelman, M. Maybery, A. O’Brien-Malone, M. Anderson, \& C. L. Macleod (Eds.), Implicit and explicit mental processes (pp. 119-132). Mahwah, NJ: Lawrence Erlbaum.

Robinson, P. (2001). Task complexity, cognitive resources, and syllabus design: A triadic framework for examining task influences on SLA. In P. Robinson (Ed.), Cognition and second language instruction (pp. 285-318). Cambridge, UK: Cambridge University Press.

Rose, R. \& Anthony, L. (2010). Concept building and discussion: Applications. Tokyo, Japan: DTP.

Rumelhart, D. E. \& McClelland, J. L. (1986). On learning the past tenses of English verbs. In J. L. McClelland \& D.E. Rumelhart (Eds.), Parallel distributed processing:Vol. 2. Psychological and biological models (pp. 216-271). Cambridge, MA: MIT Press.

Sato, R. (2010). Reconsidering the effectiveness and suitability of PPP and TBLT in the Japanese EFL classroom. JALT Journal, 32(2), 189-200.

Seki, S., Kato, K., Chamoto, T., Nagakura,Y., Miura,T., \& Watari,Y. (2011).To what degree can the grammar-translation classroom cope with contemporary college-entrance English examinations? Journal of the Chubu English Language Education Society, 40, 315-322.

Sheppard, C. (2006). The effect of instruction directed at the gaps second language learners noticed in their oral production (Unpublished doctoral dissertation). University of Auckland, Auckland, New Zealand.

Sheppard, C. (2016, September). Instructional intervention in between task repetitions and second language development. In Shintani, N. (Chair), Impact of task repetition on L2 learning: Multiple perspectives. Colloquium conducted at the Pacific Second Language Research Forum 2016, Chuo University, Tokyo, Japan.

Sheppard, C. (2019). Academic lecture comprehension. Tokyo, Japan: CELESE.

Sheppard, C., \& Ellis, R. (2018). The effects of awareness-raising through stimulated recall on the repeated performance of the same task and on a new task of the same type. In M. Bygate (Ed.), Learning language through task repetition (pp. 171-192). Amsterdam, The Netherlands: John Benjamins.

Sheppard, C., \& Ellis-Tanaka, N. (2011, November). The evaluation of a task-based curriculum for EST. Poster presented at the Fourth International Task-Based Language Teaching Conference, Auckland University, Auckland, New Zealand.

Skehan, P. (1998). A cognitive approach to language learning. Oxford, UK: Oxford University Press. 


\section{Sheppard}

Skehan, P. (2018). Second Language Task-Based Performance: Theory, research, assessment. New York: Routledge.

Swain, M. (1995). Three functions of output in second language learning. In G. Cook \& B. Seidlhofer (Eds.), Principle and practice in applied linguistics: Studies in honour of $H$. G. Widdowson (pp. 125-144). Oxford, UK: Oxford University Press.

Van den Branden, K. (Ed.). (2006). Task-based language education. From theory to practice. Cambridge, UK: Cambridge University Press.

VanPatten, B. (1990). Attending to form and content in the input: An experiment in consciousness. Studies in Second Language Acquisition, 12(3), 287-301. 